\title{
PENGEMBANGAN BUDIDAYA LEBAH MADU LOKAL "KELE- KELE" (Trigona Spp) PADA MASYARAKAT PINGGIRAN HUTAN DI KECAMATAN PUPUAN KABUPATEN TABANAN
}

\author{
M. Dewantari ${ }^{1}$, N.L.G. Sumardani ${ }^{2}$, dan I.G. Suranjaya ${ }^{3}$
}

\begin{abstract}
ABSTRAK
Kegiatan pengabdian kepada masyarakat melalui program Kuliah Kerja Nyata Pembelajaran Pemberdayaan Masyarakat yang dilakukan di Desa Kebon Padangan, Kecamatan Pupuan, Kabupaten Tabanan bertujuan meningkatkan pendapatan masyarakat sasaran melalui peningkatan produktivitas dan pemasaran madunya. Metode kegiatan yang diterapkan dalam pemberdayaan masyarakat pada program Kuliah Kerja Nyata Pembelajaran Pemberdayaan Masyarakat adalah sebagai berikut:(1)Sosialisasi dan koordinasi dengan mitra sasaran (2).Penyuluhan dan pelatihan singkat mengenai teknologi budidaya lebah madu lokal"kele-kele" (Trigona Spp) dan (3) Pendampingan secara berkala dan berkelanjutankepada mitra sasaran hingga iptek yang dialihkan dapat dilaksanakan secara mandiri. Sedangkan pelaksanaan kegiatan alih teknologi budidaya lebah madu lokal "kele-kele" (Trigona Spp) meliputi (1) Koordinasi dan komunikasi secara partisipasif dengan kelompok sasaran untuk merumuskan program mulai dari perencanaan, operasional dan evaluasi ; (2) Penyuluhan teknik budidaya lebah madu "kele-kele" serta pelatihan manajemen kelompok lebah madu dan (3) Pelatihan pemindahan koloni, rancang bangun stup sistem kotak dan pendampingan budidaya lebah madu lokal "kele-kele" (Trigona Sp) dan (4) Monitoring dan Evaluasi. Hasil dari kegiatan ini menunjukkan bahwa semua kegiatan yang dilakukan berjalan dengan lancar serta mendapat resppon yang positip dari Kepala Desa beserta jajaran aparat desanya serta kelompok lebah madu.
\end{abstract}

Kata kunci : Budidaya, Lebah Madu Lokal "Kele- Kele”(Trigona Sp), Masyarakat, Pinggiran Hutan

\begin{abstract}
Community service through Community Work Program for Community Empowerment Learning in Kebon Padangan Village, Pupuan District, Tabanan Regency aims to increase the income of the target community through increasing the productivity and marketing of honey. The method of activities applied in community empowerment in the Community Empowerment Learning Work Program Real Work are as follows: (1) Socialization and coordination with target partners (2). Briefing and brief training on local honey bee culture technology "kele-kele" (Trigona Spp ) and (3) Regular and ongoing mentoring to the target partners until the transferred science and technology can be carried out independently. While the implementation of technology transfer activities of local honey bee "kele-kele" (Trigona Spp) includes (1) Participatory coordination and communication with the target group to formulate programs ranging from planning, operational and evaluation; (2) Extension of "kele-kele" honey bee cultivation techniques and honeybee group management training and (3) Training of colony removal, box system design and mentoring of "kele-kele" local honey bees (Trigona Sp) and (4) ) Monitoring and Evaluation. The results of this activity showed that all activities carried out went smoothly and received positive responses from the Village Head and his village officials and honey bee groups.
\end{abstract}

\footnotetext{
${ }^{1}$ Fakultas Peternakan Universitas Udayana, madedewantari59@gmail.com

${ }^{2}$ Fakultas Peternakan Universitas Udayana, nlg sumardani@unud.ac.id

${ }^{3}$ Fakultas Petrnakan Universitas Udayana, gedesuranjaya@unud.ac.id
} 
Keywords: "Kele Kele" local honey bee farming (Trigona Spp), Forest Edge Communities

\section{PENDAHULUAN}

Desa Kebon Padangan merupakan salah satu desa di Kecamatan Pupuan Kabupaten Tabanan. Luas wilayahnya mencapai 15,23 km2. Jumlah penduduk untuk Desa Kebon Padangan sebanyak 3515 jiwa dengan komposisi 2249 laki-laki dan 1266 perempuan yang terbagi dalam $1257 \mathrm{KK}$. Mata pencaharian penduduk hampir $74 \%$ hidup dari pertanian dalam arti luas, $14 \%$ dari sektor jasa dan sisisanya $12 \%$ sebagai pegawai/karyawan. Desa ini dipilih sebagai lokasi pelaksanaan program Kuliah Kerja Nyata Pembelajaran Pemberdayaan Masyarakat (KKN PPM) pengembangan budidaya lebah madu lokal "kele-kele"(Trigona Spp). Kawasan ini sangat cocok sebagai lokasi pengembangan budidaya lebah madu kele-kele karena lokasinya berada didaerah pinggiran hutan (seluas 426,9 ha) dan kebun kopi (seluas 188,4 ha) dengan potensi sumber daya alam untuk lebah madu berupa ketersediaan bunga vegetasi hutan dan bunga kopi yang berlimpah sebagai sumber pakan lebah. Disamping itu juga sudah ada kelompok lebah madu 'Dharma Guna" yang beranggotakan 10 orang didesa tersebut telah mulai membudidayakan lebah madu lokal "kelekele" untuk dapat menunjang pendapatannya.

Menurut Surata (2017), lebah madu lokal "kele-kele" ( Trigona Sp) merupakan lebah tanpa sengat yang menghasilkan propolis dan polen selain madu. Lebah pekerja memiliki kepala besar dan rahang panjang. Sedang lebah ratu berukuran 3-4 kali ukuran lebah pekerja, perut besar mirip laron, berwarna kecoklatan dan mempunyai sayap pendek. Faktor yang sangat berpengaruh dalam perkembangan lebah ini adalah faktor ketersediaan pakan dan faktor lingkungan seperti temperatur udara, kelembaban udara, curah hujan dan ketinggian tempat sangatlah berpengeruh, Disamping juga kebersihan dan keamanan stup, penggunaan stup yang modern, penerapan teknik budidaya lebah yang baik, serta pengendalian hama dan penyakit lebah sangattlah berkaitan dalam upaya peningkatan produksi baik kualitas maupun kuantitasnya. Dengan meningkatnya produksi madu, nanti pada akhirnya diharapkan dapat meningkatkan pendapatan kelompok lebah madu khususnya dan masyarakat desa Kebon Padangan umumnya.

Namun permasalahannya adalah manajemen kelompok masih kurang terutama dalam budidaya lebah madu, penggunaan stup (kotak lebah) belum sesuai anjuran, Persoalan lain juga adalah masih lemahnya kemampuan sumber daya kelompok dalam penerapan teknologi baik dalam budidaya, penanganan pasca panen maupun pemasaran hasilnya. Dari permasalahan tersebut akan berdampak pada belum optimalnya hasil yang diperoleh karena produktivitas lebah madunya yang masih rendah, baik dari segi kualitas maupun kuantitasnya. Dengan demikian kontribusi terhadap peningkatan pendapatannya juga belum optimal..

Berdasarkan hal tersebut, maka untuk mengoptimalkan potensi yang dimiliki masyarakat desa Kebon Padangan, Kecamatan Pupuan, Kabupaten Tabanan dengan mengimplentasikan teknologi sebagai inovasi dalam pemberdayaan masyarakatnya maka melalui program KKN-PPM dengan kegiatan pengembangan budidaya lebah madu lokal' kele-kele" (Trigona Spp) sistem stup dilakukan untuk dapat menunjang peningkatan pendapatan masyarakatnya.

\section{METODE PELAKSANAAN}

Metode yang diterapkan pada pemberdayaan kelompok mitra sasaran ini sebagai berikut: (1) Sosialisasi dan koordinasi dengan kelompok mitra sasaran, 2). Penyuluhan dan pelatihan singkat mengenai teknologi budidaya lebah madu lokal "kele-kele" (Trigona Spp)., dan (3) Pendampingan secara berkala dan berkelanjutan kepada kelompok sasaran hingga ipteks yang dialihkan dapat dilaksanakan secara mandiri. Sedangkan pelaksanaan kegiatan alih teknologi budidaya lebah madu lokal"kele-kele" (Trigona Sp) meliputi: (1).Koordinasi dan komunikasi secara partisipasif dengan 
kelompok sasaran untuk merumuskan program mulai dari perencanaan, operasional dan evaluasi; (2). Penyuluhan teknik budidaya lebah madu dan pelatihan manajemen kelompok lebah.madu;( 3) Pelatihan pemindahan koloni, rancang bangun stup sistem kotak dan pendampingan budidaya lebah madu lokal "kele-kele' (Trigona Sp) dan (4). Monitoring dan Evaluasi.

\section{HASIL DAN PEMBAHASAN}

Pelaksanaan kegiatan ini dilakukan pada kelompok lebah madu "Dharma Guna" di Desa Kebon Padangan , Kecamatan Pupuan -Kabupaten Tabanan dengan jumlah anggota sebanyak 10 orang petani. Kegiatan dilakukan selama satu bulan mulai dari bulan Juli sampai bulan Agustus . Penyuluhan dan pelatihan singkat dilakukan 1 hari yaitu pada tanggal 28 Juli 2019 dan bertempat di Ruang Rapat Kantor Desa dengan materi : (1). Kegiatan penyuluhan tentang tata cara budidaya lebah madu lokal"kele-kele" (Trigona Sp). Sebelum dan sesudah penyuluhan dilakukan, anggota kelompok diberikan pre-test dan post- test tentang pengenalan lebah madu lokal "kele-kele', produksi lebah madu serta cara pemeliharaannya, hasilnya dapat dilihat pada Tabel 2.

Tabel 1. Tingkat Partisipasi Mitra Sasaran

\begin{tabular}{|c|c|c|c|}
\hline \multirow[b]{2}{*}{ No } & \multirow[b]{2}{*}{ Kegiatan } & \multicolumn{2}{|c|}{ Partisipasi } \\
\hline & & $\begin{array}{l}\text { Kelompok Lebah } \\
\text { (orang) }\end{array}$ & $\%$ \\
\hline 1 & $\begin{array}{l}\text { Penyuluhan dan Pelatihan singkat teknik } \\
\text { budidaya lebah madu serta manajemen } \\
\text { kelompok } \\
\text { : Kehadiran } \\
\text { - Tertarik \& mengungkapkan masalah }\end{array}$ & $\begin{array}{c}10 \\
6\end{array}$ & $\begin{array}{c}100 \\
60\end{array}$ \\
\hline 2 & $\begin{array}{l}\text { Demonstrasi } \\
\text { - Rancang bangun stup sistem kotak } \\
\text { - Pelatihan teknik pemindahan koloni }\end{array}$ & $\begin{array}{c}10 \\
6\end{array}$ & $\begin{array}{c}100 \\
60\end{array}$ \\
\hline 3 & $\begin{array}{l}\text { Monitoring dan Evaluasi } \\
\text { - Pre- test } \\
\text { - Post -test }\end{array}$ & $\begin{array}{l}10 \\
10\end{array}$ & $\begin{array}{l}100 \\
100\end{array}$ \\
\hline
\end{tabular}

Ini artinya tim penyuluh sudah berhasil memberikan materi kepada anggota kelompok. Dalam penyuluhan disamping diberikan materi tentang pengenalan lebah madu lokal "kele-kele"(Trigona $S p p$ ), juga diberikan materi tentang produksi beternak lebah, serta, cara budidaya lebah madu yang baik. Masyarakat mitra sasaran nampak respponnya cukup baik dan tertarik dengan inovasi yang ditawarkan. Ini terbukti dari kehadiran yang $100 \%$ (Tabel 1), dengan rata2 pretest dan post test nya juga mengalami peningkatan. (Tabel.2).

Tabel 2. Hasil Pre-test dan Pos-test Pada Kegiatan Penyuluhan Budidaya Lebah Madu Pelatihan Manajemen Kelompok

\begin{tabular}{|c|c|c|c|}
\hline \multirow{2}{*}{ No } & \multirow{2}{*}{ Kegiatan } & \multicolumn{2}{|c|}{ Test } \\
\hline & & Pre-test & Pos-test \\
\hline \multirow[t]{4}{*}{1} & Penyuluhan budidaya lebah & & \\
\hline & - Pengenalan lebah madu lokal"kele-kele" & 50 & 85 \\
\hline & - $\quad$ Produksi Lebah & 60 & 85 \\
\hline & - $\quad$ Pemeliharaan lebah & 60 & 85 \\
\hline
\end{tabular}

\section{8 | BULETIN UDAYANA MENGABDI}


2 Manajemen Kelompok

- Dasar-dasar manajemen kelompok

40

80

- $\quad$ Fungsi dan pengembangan manajemen kelompok

Hal ini disebabkan karena dengan teknologi budidaya lebah madu lokal kele-kele" ( Trigona Spp) disamping menghasilkan madu yang khasiatnya lebih bagus daripada madu yang dihasilkan oleh lebah madu pada umumnya serta sangat bermanfaat bagi kesehatan, budidaya lebah madu lokal ini juga sangat menunjang kedepannya menjadi daya tarik wisata panen madu serta madu yang dihasilkan dapat menjadi oleh-oleh khas bagi wisatawan yang berkunjung ke Desa Kebon Padangan rencana desa ini dicanangkan sebagai desa wisata. Menurut Surata (2017) lebah madu ini adalah tergolong jinak dan tidak menyengat sehingga tidak membahayakan para wisatawan . Disamping itu pula pemeliharaannya tidak memerlukan lahan yang luas.
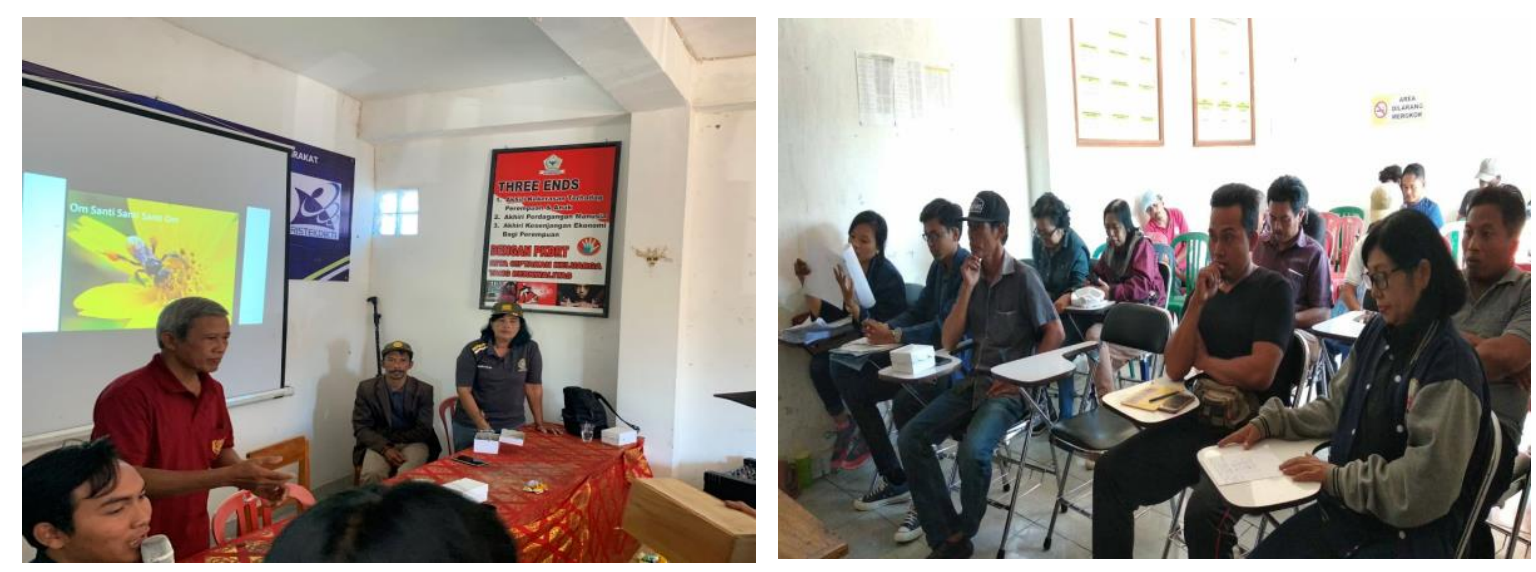

Gambar 1. Kegiatan Penyuluhan Budidaya Lebah Madu Lokal'Kele-Kele"

Kegiatan selanjutnya yaitu pelatihan manajemen kelompok lebah madu dan diberikan oleh nara sumber : Ni Ketut Seminari, SE., M.Si. Sebelum dan sesudah pelatihan, diberikan pretest dan post test serta hasiln dapat dilihat pada Tabel 2. Pada kegiatan ini dijelaskan tentang pentingnya struktur kelembagaan dalam hal ini penguatan kelompok agar nantinya kelompok tetap dapat melakukan aktivitasnya serta dapat menunjang keberlanjutannya, Disamping itu juga diberikan informasi terkait pembukuan keuangan serta pemasaran dan pengemasan produk yang baik sehingga kedepannya produk lebah madu desa Kebon Padangan dapat menjadi produk yang memiliki daya saing di pasaran dan menciptakan bisnis baru yang dapat meningkatkan pendapatan masyarakat desa Kebon Padangan. Kegiatan ini mendapat resppon positip dari anggota kelompok yang ditunjukkan dengan kehadiran langsung 100\% (Tabel 1) serta aktif dalam sesi tanya jawab.

(2) Kegiatan demonstrasi dilakukan pendampingan terhadap mitra sasaran pada teknik rancang bangun stup sistim kotak dan pemindahan koloni . Demonstrasi ini diberikan oleh I Nyoman Marnisma (teknisi lapangan) yang sudah berkompeten di lapangan dalam usaha budidaya lebah madu. Pada saat demontrasi ini berlangsung diskusi antara anggota keleompok lebah dengan ahli terkait pembuatan stup dengan berbagai ukuran, pemeliharaan stup dan cara pemindahan koloni lebah (ratu). Rancang bangun stup lebah dibuat dari kayu hutan berserat halus seperti albesia atau kayu pandan hutan dengan ukuran standar yang digunakan $40 \times 20 \times 15 \mathrm{~cm}$ dan $30 \times 15 \times 10 \mathrm{~cm}$ 
berbentuk kotak sehingga disebut stup sistem kotak. Stup lebah bisa digantung atau disusun pada rak dan diletakkan ditempat teduh. Pemeliharaan stup dilakukan secara rutin dan periodik, meliputi pengecekan kondisi stup agar tidak terkena hujan serta pembersihan dari sarang semut/laba-laba. Serta dihindari pula dari hama pengganggu seperti cecak, tokek, larva kumbang, tawon dan lainlainnya. Pada pelaksanaan program KKN PPM ini juga diserahkan bantuan sebanyak 20 stup yang sudah berisi lebah kepada kelompok lebah madu "Dharma Guna" di Desa Kebon Padangan. Selanjutnya dilakukan juga pedampingan pada simulasi pemindahan koloni lebah (ratu) dari satu stup ke stup lainnya. Hal ini penting dilakukan untuk diperhatikan. Secara teknis, pemindahan koloni. lebih mudah dengan cara memindahkan ratunya terlebih dahulu dan secara otomatis anggota koloni akan mengikuti ratu berpindah tempat (Surata, 2017). Pada saat demonstrasi dilakukan, hanya ada 6 orang (60\%) dari total anggota kelompok (Tabel 1) yang dapat dan mampu melakukan pemindahan koloni dengan baik dan benar. Hal ini sesuai dengan pendapat Baiquni (1999) bahwa inovasi yang diberikan tidak semestinya dapat dilakukan oleh seluruh anggota mitra sasaran.

Resppon mitra sasaran yakni kelompok lebah madu "Dharma Guna" Desa Kebon Padangan cukup baik, terbukti dari kehadiran dan partisipasi anggota kelompok pada beberapa tahapan kegiatan berkisar antara $60-100 \%$ (Tabel 1). tingkat pengetahuannya meningkat dari rata-rata nilainya 65 menjadi 85. Setelah semua kegiatan ini selesai Kepala Desa beserta kelompok mitra sasaran merasa sangat senang dan meresppon positip serta betekad untuk membudidayakan lebah madu lokal "kele-kele" (Trigona Spp) dengan harapan nantinya disamping dapat meningkatkan pendapatan ,kelompok khususnya maupun masyarakat desa umumnya, juga dikembangkan untuk menjadi daya tarik wisata panen madu serta madu yang dihasilkan dapat menjadi oleh-oleh khas bagi wisatawan yang berkunjung ke Desa Kebon Padangan apabila nantinya desa ini dikembangkan menjadi desa wisata. Pengembangan desa wisata membutuhkan atraksi wiiata yang spesifik dan otentik dari wilayah desa tersebut sehingga wisatawan tertarik untuk datang. (Sardiana and Ramaswati, 2016). Pengembangan wisata lebah madu ini akan menjamin keterlibatan masyarakat atau pengembangan riwisata berbasis masyarakat dalam pengembangan pariwista, sebagai ciri dari desa wisata (Sardiana and Ramaswati, 2017; Sardiana, 2018)
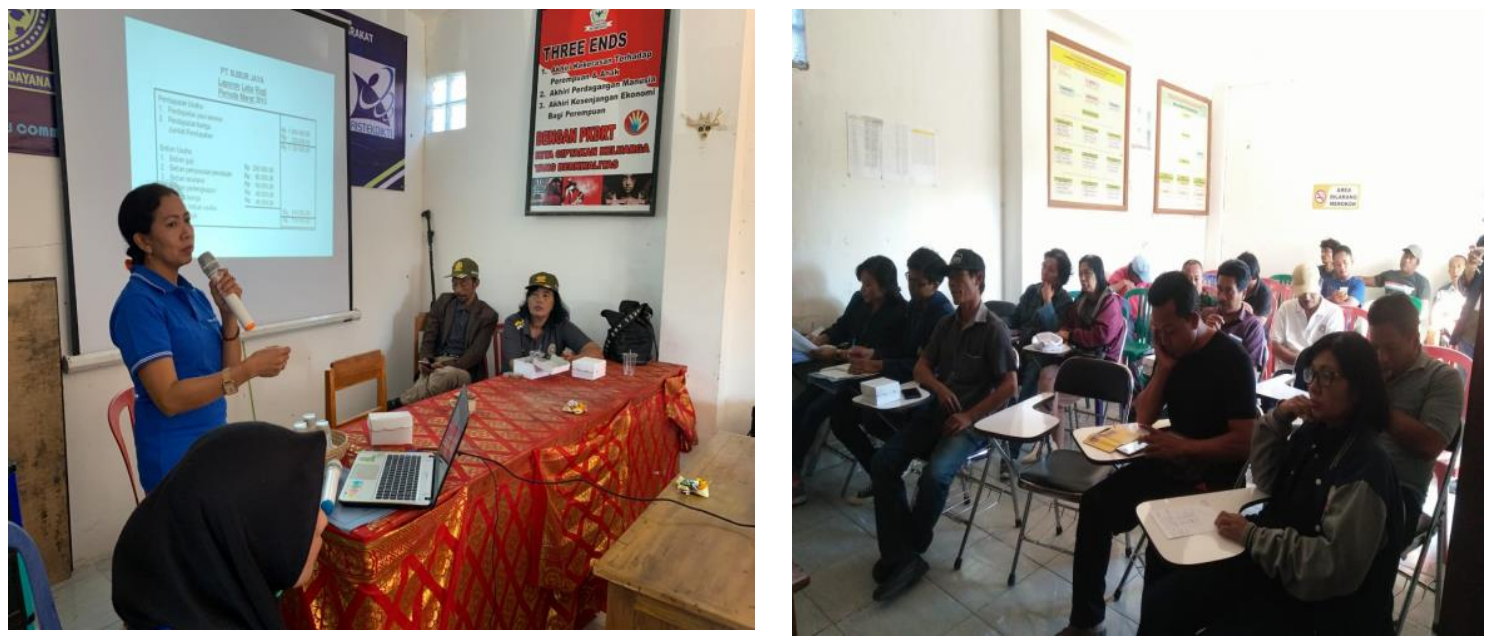

Gambar 2 Pelatihan Manajemen Kelompok Lebah Madu

\section{KESIMPULAN DAN SARAN}

\section{Kesimpulan}


Kegiatan pemberdayaan masyarakat melalui program KKN-PPM di Desa Kebon Padangan, Kecamatan Pupuan, Kabupaten Tabanan berupa pengembangan budidaya lebah madu lokal "kelekele" (Trigona Spp) dapat berlangsung dengan baik yang ditunjukkan dengan adanya partisipasi aktif dari kelompok sasaran serta ipteks yang ditawarkan dapat diterima oleh kelompok sasaran. Partisipasi aktif kelompok mitra sasaran pada seluruh tahapan kegiatan dikatagorikan cukup baik yaitu berkisar $60-100 \%$ atau secara rata-rata sebesar $80 \%$

\section{Saran}

Perlunya dilakukan pendampingan secara berkelanjutan agar inovasi yang diberikan dapat diterapkan secara tepat guna sehingga mampu nantinya menghasilkan madu yang optimal dan berkualitas.

\section{UCAPAN TERIMA KASIH}

Penulis mengucapkan terimakasih yang sebesar-besarnya kepada Direktorat Riset dan Pengabdian Masyarakat Kemenristek Dikti atas dana yang telah diberikan sehingga kegiatan ini dapat dilaksanakan. Terimakasih pula penulis sampaikan kepada Ketua Lembaga Pengabdian kepada Masyarakat, Tim KKN PPM, Kepala Desa Kebon Padangan , para Kepala Dusun dan Kelompok Lebah Madu Dharma Guna serta mahasiswa KKN PPM yang telah membantu kelancaran kegiatan ini sehingga kegiatan dapat terlaksana sesuai harapan.

\section{DAFTAR PUSTAKA}

Baiquni, M. 1999. Metode dan Teknik Partisipasi dalam Pengembangan Perdesaan. Jogjakarta: UGM-Press. Chambers, R. 1987 Pembangunan Desa Mulai dari Belakang. (Pepep Sudradjat, penerjemah). Jakarta : LP3ES.

Sihombing, D.T.H.2005. Ilmu Ternak Lebah Madu. Gadjah Mada University Press.

Sardiana, IK., NLR Purnawan., 2016. Indigenous community, ecotourism and sustainability: Experience from Tenganan Dauh Tukad traditional. Heritage, Culture and Society: Research agenda and best practices in the hospitality and tourism ind | vol: | issue : | 2016-01-01 | Conference Proceedin

Sardiana, IK., NLR Purnawan. 2015. Community-based Ecotourism in Tenganan Dauh Tukad: An Indigenous Conservation Perspective. Jurnal Kajian Bali (Journal of Bali Studies) 5 (2), 347-368

Sardiana, IK. 2018. The Study of Development of Urban Farming Agrotourism Subak-Irrigation-Based in Sanur Tourism Area, Denpasar City, Bali. Journal of Indonesian Tourism and Development Studies 6 (1), 33-40

Surata, I.K. 2017. Budidaya Lebah Madu Kele-Kele (Trigona spp.). Buku saku Pedoman Praktis. 